\title{
Drought and vegetation stress monitoring in Portugal using satellite data
}

\author{
C. Gouveia ${ }^{1,2}$, R. M. Trigo ${ }^{1,3}$, and C. C. DaCamara ${ }^{1}$ \\ ${ }^{1}$ CGUL, IDL, Faculdade de Ciências, Universidade de Lisboa, Portugal \\ ${ }^{2}$ Escola Superior de Tecnologia, Instituto Politécnico de Setúbal, Setúbal, Portugal \\ ${ }^{3}$ Departamento de Engenharias, Universidade Lusófona, Lisboa, Portugal
}

Received: 16 September 2008 - Revised: 6 January 2009 - Accepted: 14 January 2009 - Published: 18 February 2009

\begin{abstract}
Remote sensed information on vegetation and soil moisture, namely the Normalised Difference Vegetation Index (NDVI) and the Soil Water Index (SWI), is employed to monitor the spatial extent, severity and persistence of drought episodes over Continental Portugal, from 1999 to 2006. The severity of a given drought episode is assessed by evaluating the cumulative impact over time of drought conditions on vegetation. Special attention is given to the drought episodes that have occurred in the last decade, i.e., 1999, 2002 and particularly the major event of 2005. During both the 1999 and 2005 drought episodes negative anomalies of NDVI are observed over large sectors of Southern Portugal for up to nine months (out of eleven) of the vegetative cycle. On the contrary, the 2002 event was characterized by negative anomalies in the northern half of Portugal and for a shorter period (eight out of eleven months). The impact of soil moisture on vegetation dynamics is evaluated by analyzing monthly anomalies of SWI and by studying the annual cycle of SWI vs. NDVI. While in the case of the drought episode of 1999 the scarcity of water in the soil persisted until spring, in the recent episode of 2005 the deficit in greenness was already apparent at the end of summer. The impact of dry periods on vegetation is clearly observed in both arable land and forest, and it is found that arable land presents a higher sensitivity. From an operational point of view, obtained results reveal the possibility of using the developed methodology to monitor, in quasi real-time, vegetation stress and droughts in Mediterranean ecosystems.
\end{abstract}

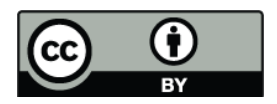

Correspondence to: C. Gouveia (cmgouveia@fc.ul.pt)

\section{Introduction}

The Iberian Peninsula is recurrently affected by drought episodes and by the adverse effects associated that range from severe water shortages to economic losses and related social impacts. For instance, during the hydrological year of 2004/05, the Iberian Peninsula was hit by one of the two worst drought episodes that were recorded in the last six decades (Garcia-Herrera et al., 2007), reinforcing the need for a continuous monitoring of vegetation stress and for reliable estimates of the drought impacts. In this respect, it is worth mentioning that, in continental Portugal alone, more than $280 \mathrm{M} €$ were spent in order to compensate for the agricultural/hydrological damage associated with the 2005 drought (MADRP, 2005).

The strong dependence of vegetation dynamics on water availability has been for long recognized in the Mediterranean and other semi-arid regions (Eagleson, 2002; Rodríguez-Iturbe and Porporato, 2004; Vicente-Serrano and Heredia-Laclaustra, 2004; Vicente-Serrano, 2007). A combined effect of lack of precipitation over a certain period with other climatic anomalies, such as high temperature, high wind and low relative humidity over a particular area may result in reduced green vegetation cover. When drought conditions end, recover of vegetation may follow (Nicholson et al., 1998) but such recovery process may last for longer periods of time (Diouf and Lambin, 2001).

Traditional methods of drought assessment and monitoring depend heavily on rainfall data as recorded in meteorological and hydrological networks. However the recent availability of reliable satellite imagery covering wide regions over long periods of time has progressively strengthen the role of remote sensing in environmental studies, in particular in those related to drought episodes (Kogan, 1995, 1997, 2000; Kogan et al., 2004; McVicar and Jupp, 1998, 1999,

Published by Copernicus Publications on behalf of the European Geosciences Union. 
2002). Drought early warning and monitoring tools are crucial components of drought awareness and mitigation plans (Wilhite, 1993) and it is worth stressing that, with the help of environmental satellites, drought episodes can be detected 4-6 weeks earlier than before and delineated more accurately (Kogan, 2000).

In recent years there has been a considerable amount of studies dealing with drought events over different regions of Europe or even covering the entire European continent (Briffa et al., 1994; Gibb et al., 1978; Marsh and Lees, 1985; Phillips and McGregor, 1998; Bussay et al., 1999; Estrela et al., 2000; Lana et al., 2001; Lloyd-Hughes and Saunders, 2002). Summer droughts are the most important in terms of human perception, but water shortages during the remaining seasons may also pose significant socio-economic impacts (EEA, 2001). Several authors have examined the special case of the Iberian Peninsula (e.g. Garcia-Herrera et al., 2007; Vicente-Serrano, 2006) and it may be noted that, even though the recent 2005 drought has been ranked among the strongest ones of the last century in Portugal, the episodes of 1945, 1981, 1983, 1992 and 1999 were also major events (Feio and Henriques, 1986). In addition, a slight downward trend has been found in the annual precipitation recorded over Portugal (Zhang et al., 1997; Miranda et al., 2006) that is particularly noticeable in early spring (Trigo and DaCamara, 2000; Paredes et al., 2006). However, less attention has been paid to the impacts of drought in vegetation activity as well as to the sensitivity of the photosynthetic mechanisms to water stress.

The aim of the present work is to make use of remotesensed information in order to monitor the spatial and temporal distribution of drought conditions on vegetation cover in Continental Portugal. The severity of a given drought episode will then be assessed by evaluating the cumulative impact over time of heat and water stress conditions on vegetation in a certain region. Special attention will be devoted to the above mentioned extreme drought episode of 2005 , as well as to those that took place in 1999 and 2002. It is worth stressing that the latter episode has mainly affected Northeastern Portugal in strong contrast with the other two episodes that have struck hardest Southern Portugal.

\section{Data}

The response of vegetation was assessed based on fields of Normalised Difference Vegetation Index (NDVI) as derived from images acquired by the VEGETATION instrument onboard both SPOT 4 and SPOT 5 satellites. VEGETATION is an optical multi-spectral instrument that performs an almost complete cover of the Earth surface in four spectral bands, on a daily basis (Hagolle et al., 2005). NDVI data were extracted from the so-called S10 products of the VITO database (http://free.vgt.vito.be), which are supplied at the resolution of $0.008928^{\circ}$ (i.e., about $1 \mathrm{~km}^{2}$ resolution at the equator) in geographic coordinates (Lat/Lon). However, we have re- stricted the analysis to the region extending from $37^{\circ} \mathrm{N}$ to $42^{\circ} \mathrm{N}$ and from $9^{\circ} \mathrm{W}$ to $6^{\circ} \mathrm{E}$ and to the period that spans from September 1998 to July 2006.

It may be noted that supplied values of NDVI were derived from atmospherically corrected and geometrically calibrated data. Radiometric corrections of instrument calibration effects rely on a linear model that normalizes the ChargeCoupled Device (CCD) response. Geometric corrections aim at mitigating the usual inherent system effects like satellite; location and orientation. The correction of atmospheric effects includes both absorption and scattering processes and is based on a modified version of the Simple Method for the Atmospheric Correction (SMAC) code (Rahman and Dedieu, 1994; Vermote et al., 1997). Further details on the corrections methods may be found in Maisongrande et al. (2004).

It is worth stressing that choice of VGT-NDVI in detriment of longer NDVI datasets (e.g. based on NOAA-AVHRR data) was motivated by the higher resolution provided by the VEGETATION instrument which allows a proper quantification of the land cover types associated to each drought event. Moreover, this study was developed within the framework of the European funded project CIRCE (Climate change and Impact Research: the Mediterranean Environment) and no NDVI-AVHRR data, covering 2004/05 (even at lower resolutions) was found accessible in useful time.

NDVI fields from VITO are provided on a 10-day basis as derived using the Maximum Value Composite method (MVC), which simply consists in selecting, for each pixel, the date of maximum NDVI among 10 consecutive daily images (Holben, 1986). Time series of MVC-NDVI composites have proven to be a source of valuable information for monitoring surface vegetation dynamics at the global and the regional scales (Zhou et al., 2001; Lucht et al., 2002; Nemani et al., 2003). Despite its usefulness this dataset presents some caveats related with cloud contamination, shadows and snow, sun/view directional dependence of the spectral response as well as with the dependence of phenological changes both on time of observation and on geographical location.

In order to create a consistent dataset of vegetation phenology, the yearly time-series of VGT-NDVI were analysed and corrected, following the method proposed by Stockli and Vidale (2004). The method has been successfully applied to the Pathfinder NDVI data in order to create a continuous European vegetation phenology dataset of 10-day temporal and $0.1^{\circ}$ spatial resolution. Their approach involves two steps in the spatio-temporal interpolation process; i) a replacement of no-data values in the dataset by spatial interpolation and ii) an adjustment of the NDVI time-series by using a temporal interpolation procedure. The methodology relies on the application of an adjustment algorithm based on a weighted second-order Fourier analysis of the data, as previously described by Sellers et al. (1997) and Los (1998). This approach uses different correction procedures for the growing and the non-growing season and therefore requires a precise definition of the growing season, which in Portugal usually 
starts with the hydrological year, i.e. year N starts in September of year N-1 and ends in August of year N. The correction method was applied to VGT-NDVI 10-day composites with $1 \mathrm{~km}$ spatial resolution for the period from September of 1998 to July 2006.

Since a quick response of vegetation to spatio-temporal variations in soil moisture is generally observed in semiarid regions (Bonifacio et al., 1993; Sannier and Taylor, 1998), the impact of soil moisture on vegetation dynamics is also worth being analysed. We have relied on the Global Soil Moisture Archive (http://www.ipf.tuwien.ac.at/ radar/ers-scat/home.htm) for the period 1992-2005 (Scipal, 2002) and have extracted the so-called Soil Water Index (SWI). The database comprises global surface soil moisture together with indicators of root zone soil moisture sampled at 10-day intervals. Retrieval of soil moisture for the Global Soil Moisture Archive is based on the so-called change detection method developed by Wagner et al. (1999b). The method accounts for the effects of surface roughness, vegetation and heterogeneous land cover (Wagner et al., 1999a, b). The archive was constructed with information from the European Remote Sensing (ERS) Scatterometer instrument on-board ERS-1 and ERS-2 satellites, operated by the European Space Agency (ESA), which achieve global coverage within 3 to 4 days with a $25 \mathrm{~km}$ grid spacing. SWI fields were interpolated to a $0.25^{\circ}$ latitude-longitude grid covering the same window that was defined for NDVI. Unfortunately, due to a satellite problem, there is a gap of data between January 2001 and August 2003 undermining the use of SWI for the 2002 drought episode.

The severity of a given drought episode is often assessed by means of the so called Palmer Drought Severity Index (PDSI) that is based on a supply-and-demand model of soil moisture (Palmer, 1965). The aim of PDSI is to provide standardized measurements of moisture conditions so that comparisons can be made between locations and between months. Based on the concept of water balance, PDSI is mainly a meteorological index which responds to weather conditions that have been unusually dry or unusually wet. Details on the evaluation of PDSI, as well as about its usefulness and limitations, may be found e.g., in Alley (1984). The index is usually computed on a monthly basis and has proven as especially adequate to characterise long-term droughts. Values of PDSI, which roughly vary between -6.0 and +6.0 are derived from the following relationship

$X_{i}=0.897 X_{i-1}+\frac{Z_{i}}{3}$

where $X_{i}$ and $Z_{i}$ respectively denote the monthly values for month $i$ of PDSI and the so-called moisture anomaly index which takes into account the difference between the actual precipitation in month $i$ and the amount of precipitation that is "climatologically appropriate" for the existing conditions (Palmer, 1965). Since the first term of Eq. (1) introduces an

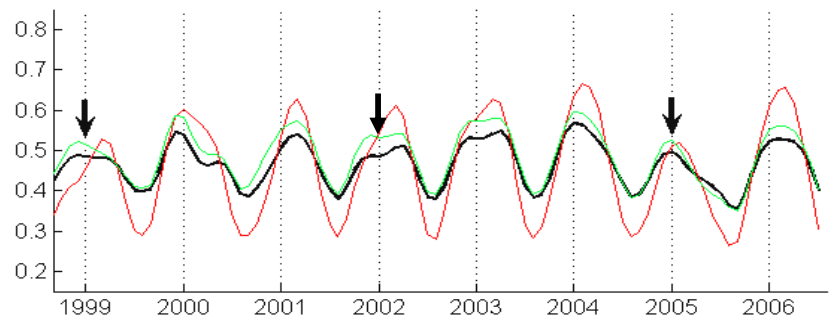

Fig. 1. Monthly time-series (1999-2006) of NDVI averaged over Continental Portugal for all pixels (black line), for pixels of nonirrigated arable land (red line) and for pixels of broad-leaved forest (green line). Black arrows indicate the drought episodes of 1999 , 2002 and 2005. Vertical dotted lines indicate the month of January.

autoregressive process, PDSI has a certain length of memory (Karl, 1986).

Drought episodes are associated to negative values of PDSI and are usually grouped into the so-called drought severity classes which are defined as follows; moderate drought (PDSI $\approx-2$ ), severe drought (PDSI $\approx-3$ ) and extreme drought $(\mathrm{PDSI} \approx-4)$. Here we have used a short monthly time series of average PDSI values for Portugal available from the World Meteorological Organization (WMO, 2006).

\section{Drought assessment}

\subsection{Annual cycle of NDVI}

The temporal evolution of monthly values of NDVI, spatially averaged over Continental Portugal between 1999 and 2006, is presented in Fig. 1. Time series of monthly NDVI are also shown for three different types of land cover. It may be noted that information about the land cover type associated to each pixel was obtained from the Corine Land Cover 2000 (CLC2000) database. The years of 1999, 2002 and 2005 are characterized by low values of vegetation greenness, especially during the growing season, i.e., during the period of high photosynthetic activity. In the case of the droughts of 1999 and 2005, this is especially apparent for pixels over non-irrigated arable land, a feature that is in contrast with the case of 2002 where the lower values are well visible over broad-leaved forest. The delay of the growing season of arable land together with the observed relative insensitivity in the case of broad-leaved forest is another interesting feature, since it suggests drought conditions to be responsible for both delaying and shortening the growing season.

The evolution of monthly anomaly fields of NDVI from September to August, for the hydrological years of 1998/99, 2001/02 and 2004/05 may be observed in Figs. 2 to 4. It may be noted that monthly anomalies of a given month are defined as departures from the median of that month (computed over the considered period 1999-2006). Usage of the 


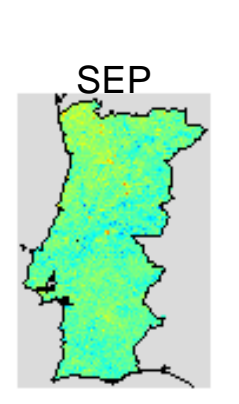

1999
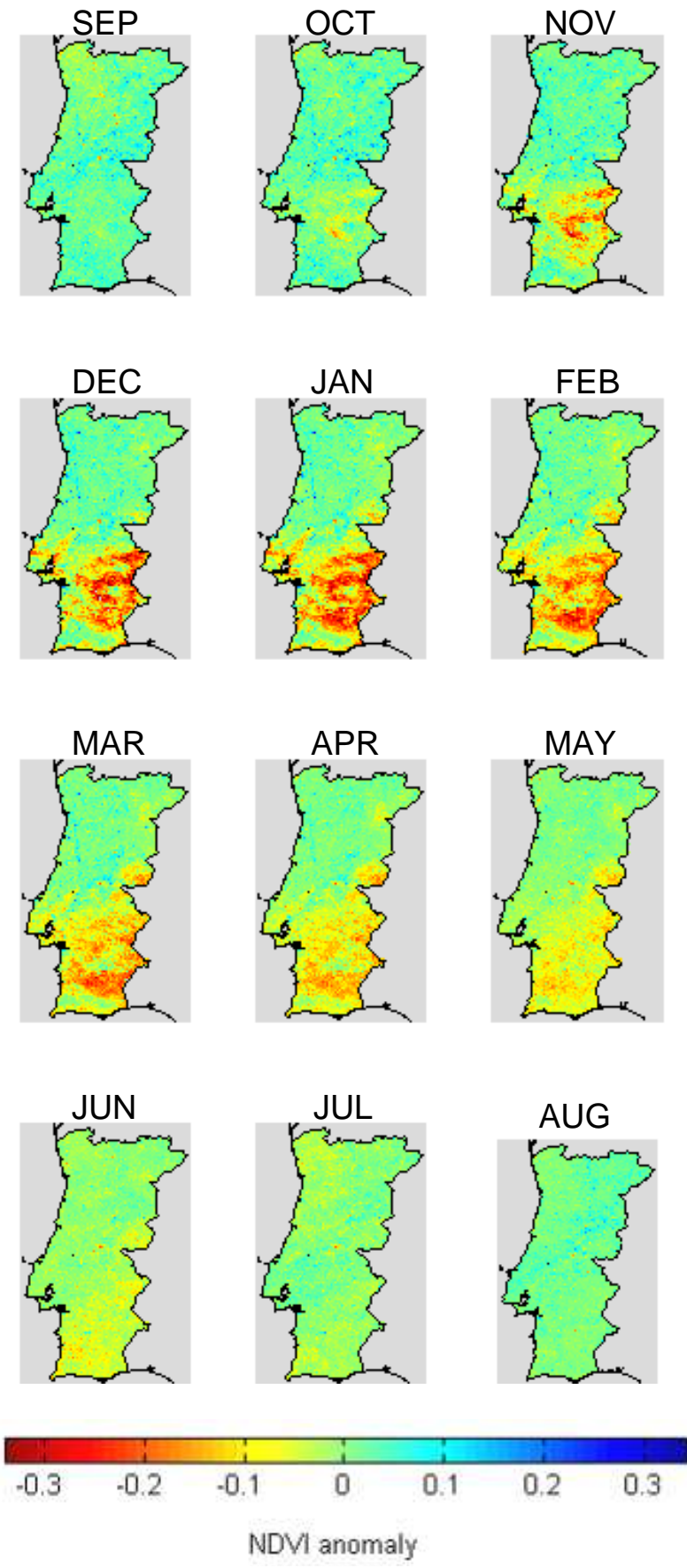

Fig. 2. Monthly NDVI anomalies from September to August, respecting to the hydrological year of 1998/99.

median (instead of the mean) was felt necessary in order to avoid the lever effect by the extremely low NDVI values that were attained during droughts years, taking into account the small length of the sample (8 years).

As already pointed out, the three chosen drought years are characterised by low vegetation greenness activity associated to low values of NDVI (Fig. 1). However these three
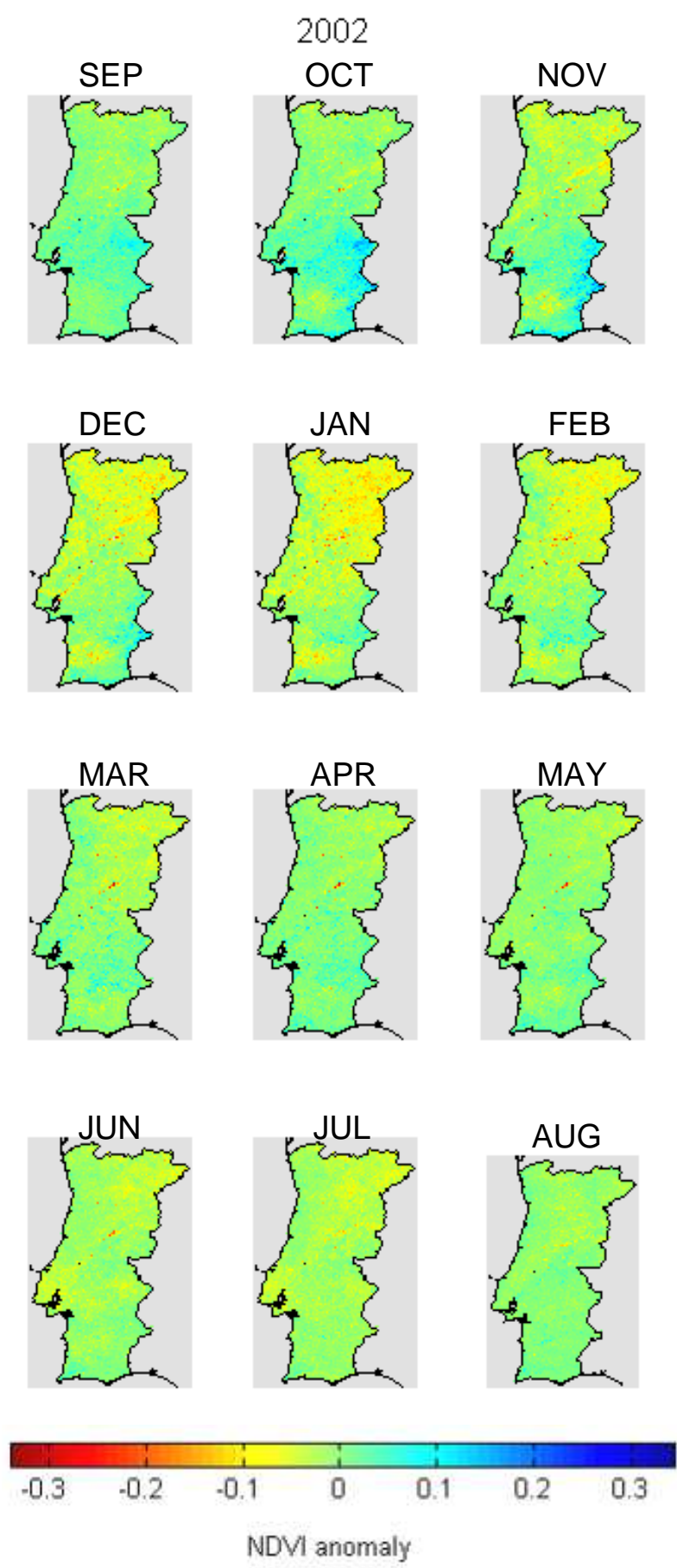

Fig. 3. As in Fig. 2 but respecting to the hydrological year of 2001/02.

events present distinctive features in their spatial and temporal evolution. In the case of 1999 (Fig. 2) the highest negative anomalies (around -0.30) appear as early as November 1998 and persistently remain until the following April. The most affected regions are located in Southern Portugal and the impact of the drought is apparent until May. A strong contrast in the spatial distribution may be observed in the 
case of 2002 (Fig. 3) with the highest negative anomalies being found over Northeastern Portugal (around -0.10) and extending from November to February. The exceptional intensity of the 2005 drought episode (Fig. 4) is well apparent, taking into account both the magnitude and persistence of negative anomalies and the large fraction of the territory that was affected. The 2005 event presents some similarities with the 1999 episode, in particular in what respects to the highest negative anomalies (around -0.30) that may be observed, over Southern Portugal, between February and June. Interestingly, starting as soon as September 2004, several small patches of highly stressed pixels may be observed over the central and southern sectors of the country. These regions correspond in fact to the areas that were burned in the previous summer of 2003, when circa 450000 ha of land were devastated by wildfires (Trigo et al, 2006).

It is worth emphasising that, in the cases of the 1999 and 2005 drought episodes, the area of stressed vegetation is located in the south of Portugal, a region that is generally covered by non-irrigated arable land, with semi-arid characteristics and presenting a strong desertification risk. It may be further noted that the location of stressed pixels is also in good agreement with the results of Vicente-Serrano (2006) who has shown that the impact of climate variability and associated extreme events (such as drought) on vegetation activity is most pronounced over arid areas. Finally, in the case of the 2005 drought episode, it is worth stressing that the observed negative anomalies are contemporaneous with the period of high photosynthetic activity, leading to a further amplification of the negative impact on vegetation dynamics and therefore to an even larger drought impact.

\subsection{Annual cycle of soil moisture}

The spatially averaged values over Portugal of SWI are presented in Fig. 5 and it is well apparent that the drought episodes of 1999 and 2005 are characterised by an annual cycle reaching values well below the remaining years. The average response of vegetation to soil moisture is illustrated in Fig. 6 that presents the annual cycle of SWI vs. NDVI as obtained from averaging both variables over the corresponding available climatologies. The initial linear relationship between NDVI and SWI from August to December translates the contemporaneous response of vegetation to soil moisture that leads to a maximum of greenness in January. However, the following period presents a non linear behaviour. The strong decrease in SWI between January and April corresponds to a slight decrease of NDVI, suggesting that vegetation greenness is sustained by the cumulated soil water during winter time. A contemporaneous response of NDVI to SWI is again observed from April to August, closing the vegetation cycle.

The temporal evolution of the spatial distribution of monthly anomalies of SWI, over Continental Portugal, for the drought episodes of 1999 and 2005 may be observed in
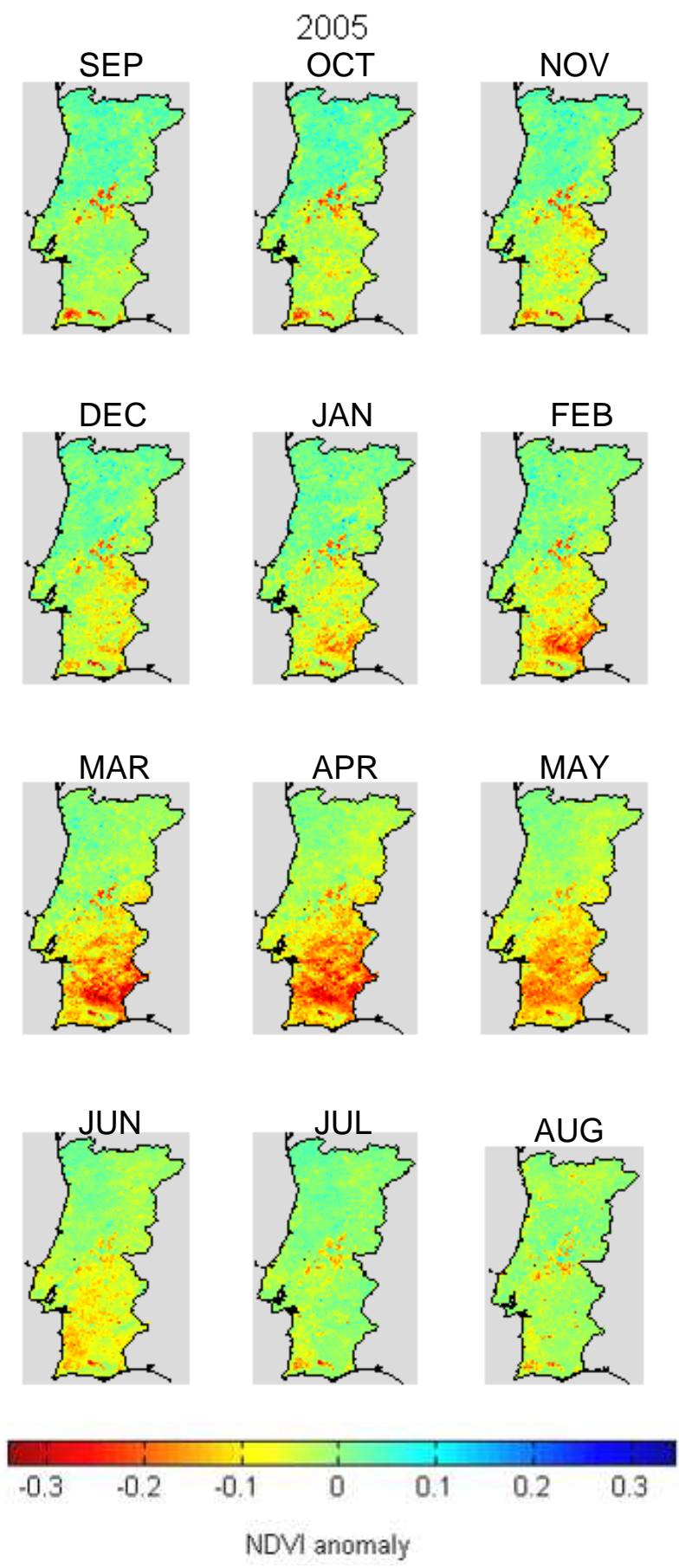

Fig. 4. As in Fig. 2 but respecting to the hydrological year of 2004/05.

Figs. 7 and 8, respectively. The drought episode of 2002 was not considered because of the above-mentioned unavailability of SWI data for the hydrological year 2001/02. SWI anomalies are defined as departures from the corresponding monthly mean over the available data within the considered 14-year period (1992-2005). As opposed to the drought episode of 2005, where the occurrence of negative anomaly 


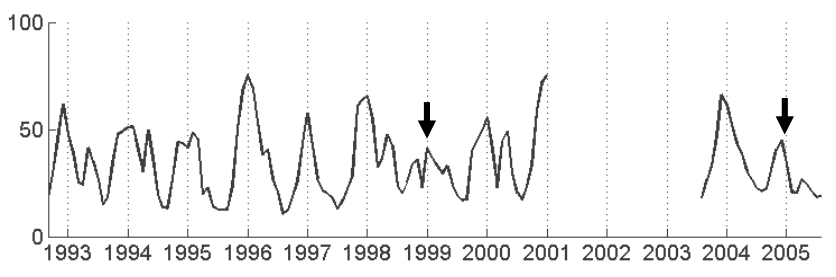

Fig. 5. Monthly time-series (1992-2005) of SWI averaged over Continental Portugal. Values from January 2001 until August 2003 are missing. Black arrows indicate the drought episodes of 1999 and 2005.

values of SWI only begin in spring, drought conditions for the 1999 event start to occur in the beginning of the 1998/99 winter.

The different impact of the soil moisture cycle on vegetation greenness in the cases of the 1999 and 2005 episodes can be appreciated in Fig. 9 that presents the respective annual cycles of SWI vs. NDVI (red line). For reference purposes the average (climatological) cycle is also represented (black curve) for both episodes. It is immediately striking the limited range of values of NDVI and SWI observed during both drought episodes. Results also point out the role of soil moisture in winter and early spring in the green-up of vegetation over semi-arid regions, where there is a high level dependence of the vegetation cover on water availability (Nicholson et al., 1990, 1998; Nicholson and Farrar, 1994; Vicente Serrano, 2006). In the case of the hydrological year 1998/99 (Fig. 9, left panel) there is a persistent shortage of soil moisture from November until May, with dramatic effects on vegetation greenness that are well apparent in the SWI vs. NDVI cycle that is almost entirely contained within the respective climatological cycle. A different behaviour may be observed in the case of the drought episode of 2004/05 where a deficit in greenness is already apparent at the beginning of September. The superavit of SWI is reflected on a slight recovery of vegetation greenness but the severe shortage of soil water from December up to May has devastating effects on vegetation activity, with NDVI values for spring (MAM) of 2005 being considerably lower than the corresponding climatological averages.

The sensitivity of the different land cover types to the available soil moisture is illustrated in Fig. 10 that presents annual cycles of spatially averaged NDVI for each year of the considered period (1999-2006) over non-irrigated arable land (top panel) and coniferous forest (bottom panel). The two drought episodes of 1999 (curve with circles) and 2005 (curve with asterisks) are enhanced and the impact of dry periods is clearly observed in the case of arable land, with minimum values occurring in winter for the 1999 event and in spring for the 2005 episode. However, over coniferous forests, lower than average values of NDVI may still be observed simultaneously in early winter and extending until summer in the case of 2005.

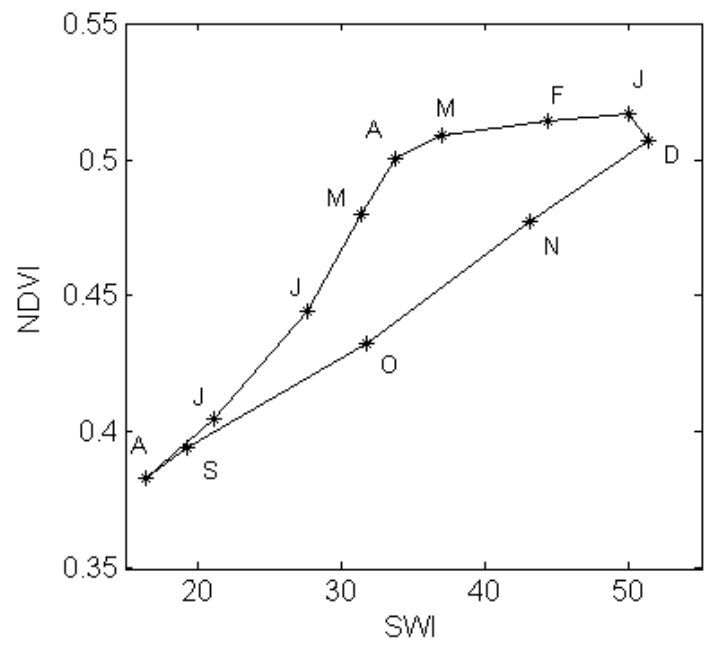

Fig. 6. Climatological cycle of monthly averages of SWI vs. NDVI. Letters indicate months of the year.

\subsection{Drought persistence}

Figure 11 presents, for the year of 2004/05, the evolution on a monthly basis (black curve) of the percentage of continental Portugal that is under extreme drought conditions according to the PDSI values obtained from WMO (2006). The corresponding monthly evolution of the percentage of the territory with stressed (black bars) and very stressed (gray bars) vegetation is also represented in the figure. It may be noted that the area of stressed (very stressed) vegetation was estimated based on the fraction of pixels with anomalies lower than 0 (lower than -0.025). The severity of the drought episode of 2005 is striking taking for instance into account that, in May, almost $90 \%$ of continental Portugal is covered by pixels with NDVI anomalies lower than 0 . Figure 11 also reveals the existence of a delay of about three months of PDSI relatively to NDVI. Such delay, that is especially visible for very stressed vegetation, translates the already mentioned memory of PDSI (Karl, 1986) due to the autoregressive process associated to the concept of PDSI. Moreover, the observed good agreement, for the 2005 drought episode, between the percentage of territory affected by extreme drought and, simultaneously associated to highly stressed vegetation, suggests adopting the value of -0.025 as a threshold to identify pixels affected by drought conditions in the remaining years of the study period. Accordingly, we have evaluated drought persistence by simply counting, for each pixel, the number of months with NDVI anomalies lower than -0.025 , for the years of 1999, 2002 and 2005. In the cases of the drought episodes of 1999 and 2005, pixels located over the south of Portugal reveal up to nine months (out of eleven) of persistently stressed vegetation between September and July of the following year. In the case of the 2002 drought episode, a considerable large area over Noutheastern Portugal presents up to eight months (out of eleven) of stressed vegetation. 


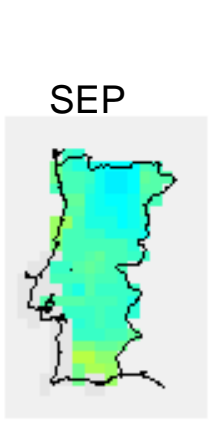

\section{9}
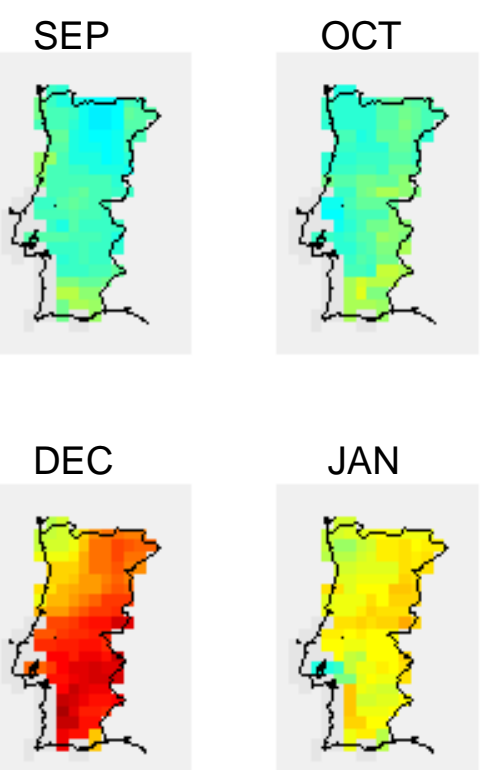

MAR
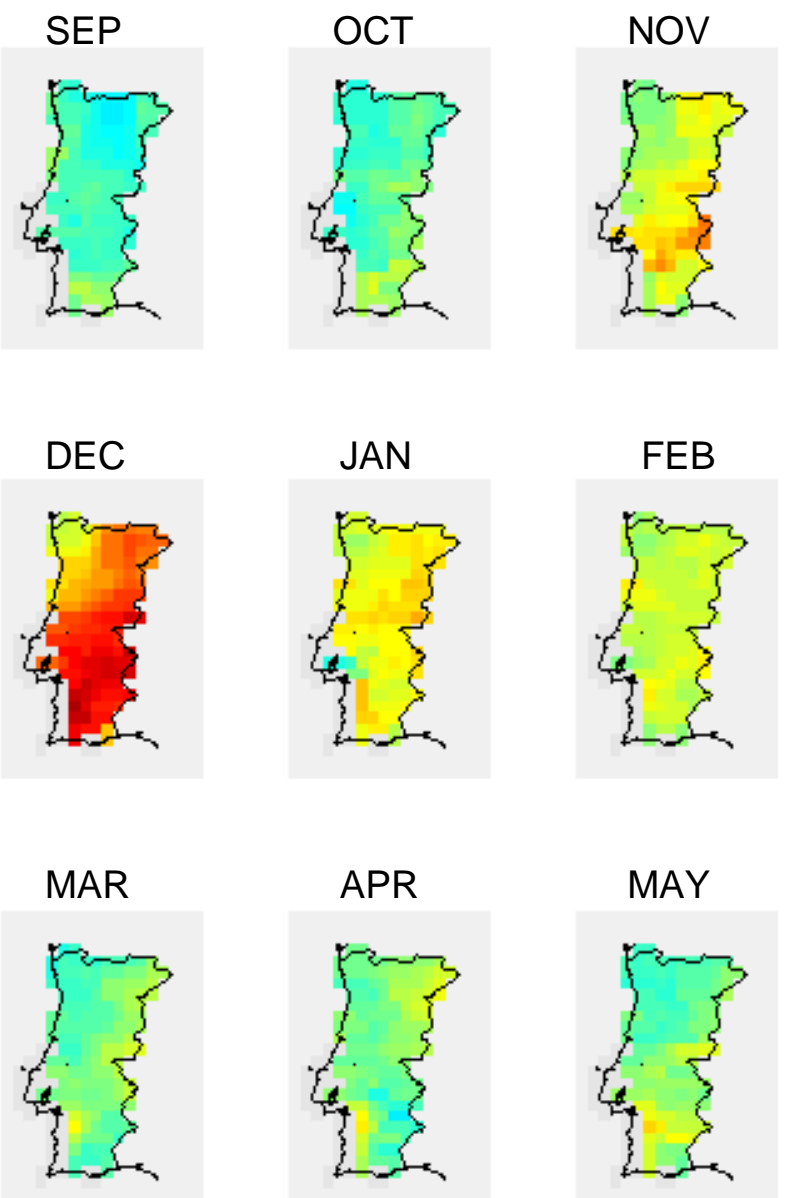

\section{FEB}

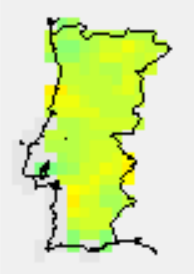

MAY

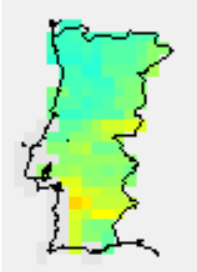

AUG

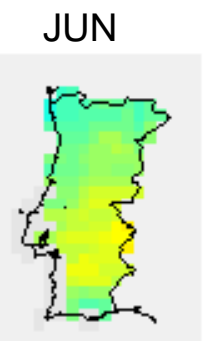

JUL

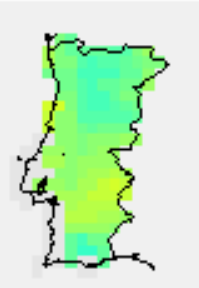

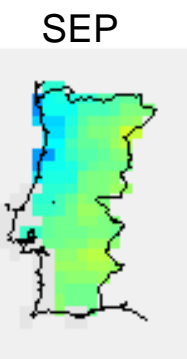

DEC

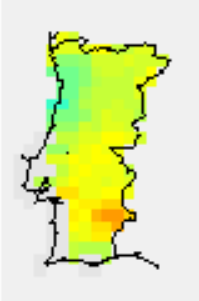

MAR

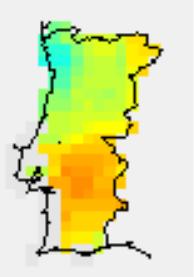

JUN

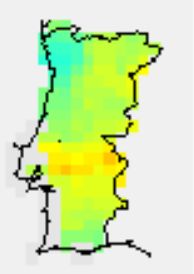

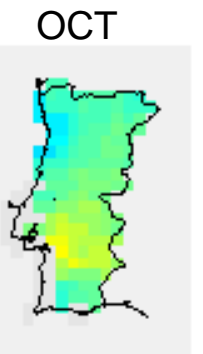

NOV

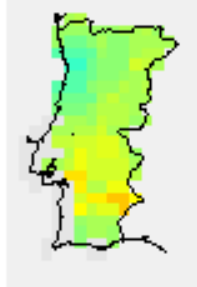

JAN

FEB
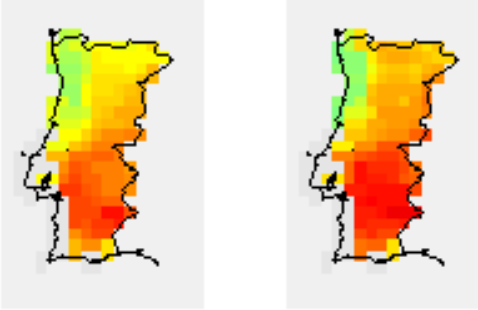

APR

MAY
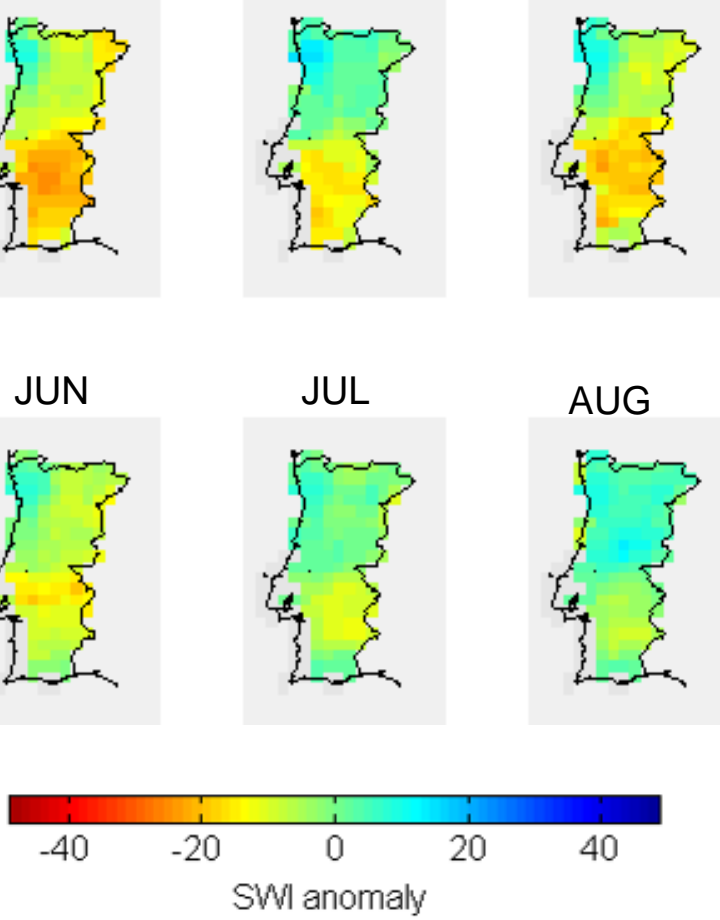

Fig. 8. As in Fig. 7 but respecting to the year 2004/05.

Fig. 7. SWI anomalies for January to August respecting to the year 1998/99.

Table 1 presents the percentage of mainland Portugal stricken by severe drought, i.e., with monthly NDVI anomalies below -0.025 in more than 9 months along the year (out of 11, i.e. excluding August). It may be noted that because August is extremely dry over Portugal and separates two con-

secutive hydrological years, its inclusion in the evaluation of drought persistence can be misleading. The exceptionality of 2005 drought episode is evident again, with more than one third of Portugal affected with more than 9 months of high vegetation stress, an area that is twice the one observed in 1999. The relatively smaller amount of $11 \%$ of mainland 
Table 1. Percentage of mainland Portugal stricken by severe drought, i.e. with monthly NDVI anomalies below -0.025 in more than 9 months (out of 11).

\begin{tabular}{lllllllll}
\hline & \multicolumn{8}{c}{ Years } \\
& 1999 & 2000 & 2001 & 2002 & 2003 & 2004 & 2005 & 2006 \\
\hline $\begin{array}{l}\text { \% mainland } \\
\text { severe } \\
\text { drought }\end{array}$ & 18 & 1 & 3 & 11 & 1 & 4 & $\mathbf{3 6}$ & 9 \\
\hline
\end{tabular}

Table 2. Total amounts and relative proportions of pixels affected by drought for different land cover types during the drought episodes of 1999, 2002 and 2005.

\begin{tabular}{|c|c|c|c|c|c|}
\hline Year & $\begin{array}{l}\text { Non-irrigated } \\
\text { Arable land }\end{array}$ & Forest & Shrubland & Other & Total \\
\hline 1999 & $\begin{array}{l}10498 \\
(25 \%)\end{array}$ & $\begin{array}{l}9375 \\
(23 \%)\end{array}$ & $\begin{array}{l}4310 \\
(10 \%)\end{array}$ & $\begin{array}{l}17206 \\
(42 \%)\end{array}$ & $\begin{array}{l}41389 \\
(100 \%)\end{array}$ \\
\hline 2002 & $\begin{array}{l}2542 \\
(9 \%)\end{array}$ & $\begin{array}{l}5125 \\
(19 \%)\end{array}$ & $\begin{array}{l}8035 \\
(30 \%)\end{array}$ & $\begin{array}{l}11094 \\
(42 \%)\end{array}$ & $\begin{array}{l}26796 \\
(100 \%)\end{array}$ \\
\hline 2005 & $\begin{array}{l}11722 \\
(22 \%)\end{array}$ & $\begin{array}{l}11841 \\
(23 \%)\end{array}$ & $\begin{array}{l}5974 \\
(11 \%)\end{array}$ & $\begin{array}{l}23032 \\
(44 \%)\end{array}$ & $\begin{array}{l}52569 \\
(100 \%)\end{array}$ \\
\hline
\end{tabular}

Table 3. Cumulative effect of drought conditions for specific land cover types during the drought episodes of 1999, 2002 and 2005.

\begin{tabular}{rrrrr}
\hline & No. Months & $\begin{array}{r}\text { Non-irrigated } \\
\text { Arable land }\end{array}$ & Forest & Shrubland \\
\hline \multirow{3}{*}{1999} & $\geq 6$ & 100 & 100 & 100 \\
& $\geq 7$ & 87 & 76 & 74 \\
& $\geq 8$ & 64 & 47 & 43 \\
2002 & $\geq 9$ & $\mathbf{3 1}$ & 17 & 18 \\
& $\geq 6$ & 100 & 100 & 100 \\
& $\geq 7$ & 72 & 66 & 74 \\
& $\geq 8$ & 48 & 43 & 53 \\
& $\geq 9$ & 29 & 26 & $\mathbf{3 4}$ \\
& $\geq 6$ & 100 & 100 & 100 \\
& $\geq 7$ & 93 & 85 & 83 \\
& $\geq 8$ & 83 & 71 & 66 \\
& $\geq 9$ & $\mathbf{6 5}$ & 54 & 50 \\
\hline
\end{tabular}

affected by the 2002 event is, nevertheless, above the remaining years for the considered period. In the cases of the drought episodes of 1999 and 2005, it is worth reinforcing that the region affected is located in southern Portugal, more precisely in the province of Alentejo, an area that is responsible for more than $80 \%$ of the total of wheat production in Portugal (Gouveia and Trigo, 2008). Drought analysis in this area is especially important, not only because droughts may cause significant economic losses (Morales et al., 2000; Iglesias et al., 2003) but also due to the fact that there is a strong dependence of the economy and society on agriculture yields (Vicente-Serrano, 2006).

We have also compared the vegetation response to water stress of different land cover types, for the three drought
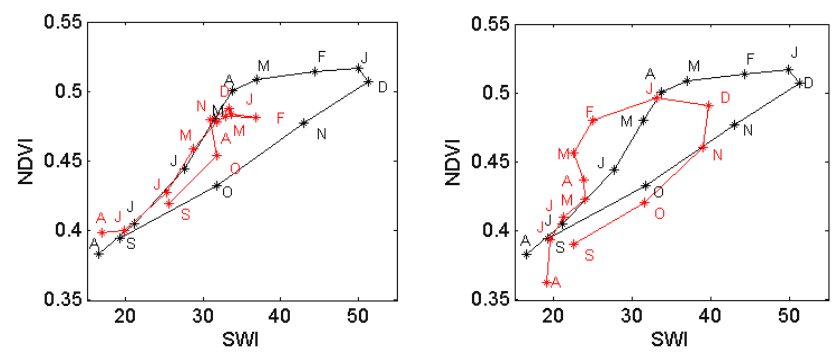

Fig. 9. Annual cycles (red curves) of SWI vs. NDVI for the drought episodes of 1998/1999 (left panel) and 2004/2005 (right panel). The climatological cycle (black curves) is also presented for reference purposes.
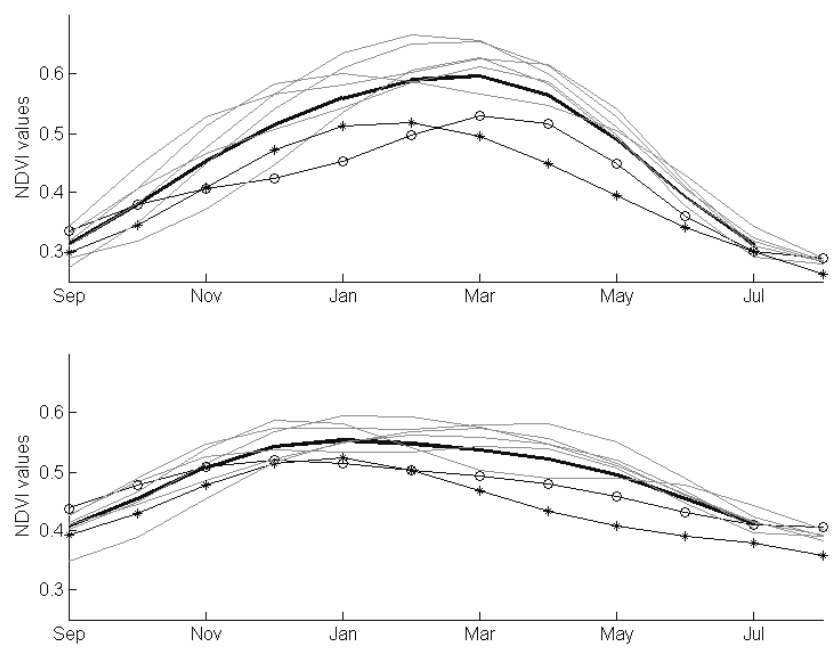

Fig. 10. Annual cycles of spatially averaged NDVI for each individual year of the considered period (1999-2006) over non-irrigated arable land (top panel) and coniferous forest (bottom panel). The drought episodes of 1999 and 2005 are represented, respectively, by the curves with circles and asterisks. The line in bold refers to monthly means over the entire period.

episodes of 1999, 2002 and 2005. As shown in Table 2, in all three episodes, non-irrigated arable land, forest and shrubland represent more than $55 \%$ of pixels characterised by at least 6 months (out of 11) of monthly NDVI below -0.025 . As expected, the episode of 2005 ranks first in what respects to the total amount of affected pixels (52569), followed by 1999 (41 389) and 2002 (26 796). However, there are interesting differences when comparing the drought episodes of 1999 and 2005 versus the episode of 2002 in what respects to the proportion of affected vegetation types. Arable land was especially affected during the 1999 and 2005 episodes (22\% and $25 \%$, respectively), whereas shrubland was the most affected land cover type during the 2002 episode (30\%). Forest was affected in similar proportions during the three drought episodes and the remaining types of vegetation do not show as well noticeable differences among episodes. 


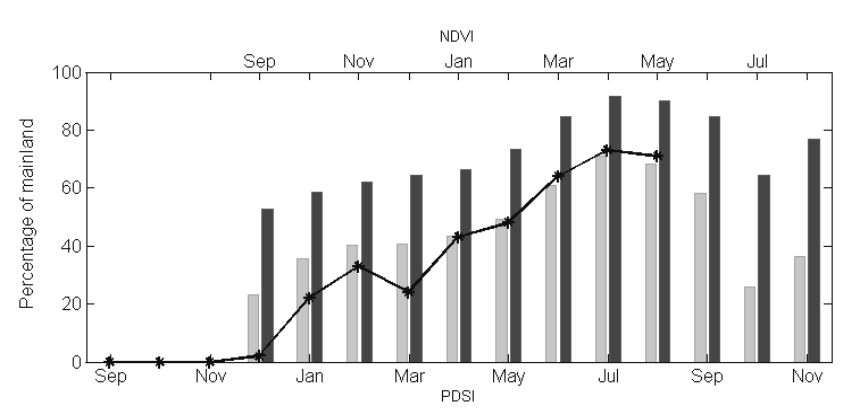

Fig. 11. Percentage of continental Portugal with monthly NDVI anomalies lower than 0 (black bars) and lower than -0.025 (gray bars), from September 2004 to August of 2005. The black line represents the percentage of mainland affected by extreme drought, i.e., with PDSI $\approx-4$. The 3-month delay of PDSI relatively to NDVI (as indicated by the two different horizontal time axes) is worth being noted.

The cumulative effect of drought conditions on the three considered types of vegetation was further investigated by analysing the relative proportions of pixels that remained with monthly anomalies of NDVI below -0.025 for 7,8 and 9 months. Results are presented in Table 3 and important differences may be found among the three drought episodes. The exceptional strength of the drought episode of 2005 is well illustrated by the high percentage of affected pixels of all vegetation types (including forest), with more than half of the pixels $(65 \%)$ being affected for 9 or more months. In the case of the drought episode of 1999 non-irrigated arable land was the main vegetation type affected, with a total amount of almost one third of the pixels $(31 \%)$ being affected for at least 9 months. The sharp difference between the percentage of non-irrigated arable land affected in the two different drought events (1999 and 2005) is worth being pointed out. This disparity is attributable both to differences in the extension of drought conditions and in the time of occurrence of the highest scarcity of soil moisture. In the case of 1999, the higher SWI negative anomaly occurs in December and there is an apparent recovery in March. However, in the case of 2005 , the anomaly starts in January and persists until June. Such a long period without soil humidity in 2005 has extremely affected the non-irrigated crops and, in particular, there was a severe shortage in the wheat yield (estimated as more than $50 \%$ when compared with the previous 15 years). Finally, in the case of the episode of 2002, shrubland was the most affected vegetation type with slightly more than one third $(34 \%)$ being affected for at least 9 months.

\section{Concluding remarks}

An assessment was made on the potential usage of environmental satellites for the detection and monitoring of drought events in Continental Portugal. For this purpose, annual cycles of vegetation greenness were analysed by examining, for each year, the monthly anomalies of NDVI. Special attention was devoted to the years of 1999, 2002 and 2005 because
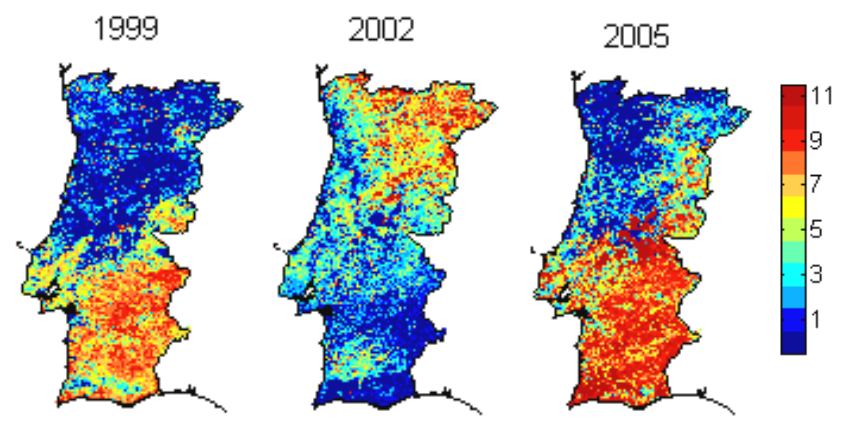

Fig. 12. Number of months between September and July that are characterised by NDVI anomaly values below -0.025 , for 1999 , 2002 and 2005.

of the occurrence of low values of vegetation greenness during the growing season. In the case of the drought episodes of 1999 and 2005, southern Portugal was mostly affected, whereas in the case of 2002 the highest negative anomalies were found in Northern Portugal.

The impact of soil moisture on vegetation dynamics was also assessed by studying the annual cycle of SWI vs. NDVI and by analysing monthly anomalies of SWI. Obtained results pointed out the different impact of the soil moisture cycle on vegetation greenness; while in 1999 shortage of water in the soil persisted from November until May, in the episode of 2005 the deficit in greenness was already apparent at the beginning of September. The sensitivity of the different land cover types to the available soil moisture was also studied. The impact of dry periods was clearly observed in both cases of arable land and forest, the former vegetation type presenting a higher sensitivity than the latter.

The relationship between PDSI and NDVI was also studied for the year of 2005. In the case of NDVI anomalies below -0.025 , the existence of a delay of about three months of PDSI relatively to NDVI suggested using this threshold to identify pixels associated to stress vegetation over western Iberia. Drought persistence was therefore assessed by counting, for each pixel, the number of months with NDVI anomalies lower than -0.025. As expected, the years of 1999, 2002 and 2005 were particularly notorious as a consequence of the large areas affected by persistent drought. The exceptionality of the 2005 event was outstanding, not only because more than one third of Portugal was covered by pixels with more than 9 months in vegetation stress, but also due to the fact that most relevant vegetation types (non irrigated arable land, forest and shrubland) were all affected. In the cases of the episodes of 1999 and 2005, persistent drought especially affected arable land, in particular over the province of Alentejo, an area that is responsible for more than $80 \%$ of the total of wheat production in Portugal. In the case of 2002, pixels under persistent stress are mainly located in Northern Portugal and shrubland was the mostly affected vegetation type.

From an operational point of view, obtained results reveal the possibility of using the developed methodology to 
monitor, in quasi real-time, vegetation stress and droughts in Mediterranean ecosystems. In fact, it is expected that the obtained results may contribute to the implementation of a semi-automated drought monitoring tool, that can guide decisions of policy makers, namely those associated to agricultural, forest and environment sectors in continental Portugal. Additionally, new results obtained in our laboratory (but not presented here) point to the possibility of using these early drought detection methods in the assessment of biomass losses as well as in building up summer maps of fire risk. Moreover, the continuous production and calibration of SPOT-VEGETATION based products (or future compatible satellite platforms) will soon provide longer time series, useful for different types of prognostic studies, namely crop forecasts and amount of water required for irrigation.

Acknowledgements. This work was supported by the Gulbenkian Foundation through project IMPACTE (No. 1568). Ricardo Trigo received support from the EU 6th Framework Program "Climate change and Impact Research: the Mediterranean Environment" (CIRCE). The authors would like to thank T. Calado for her technical support with VGT-NDVI correction. The NDVI dataset was kindly supplied by VITO database (http://free.vgt.vito.be). The SWI was provided by the Global Soil Moisture Archive (http://www.ipf.tuwien.ac.at/radar/ers-scat/home.htm).

Edited by: U. Ulbrich

Reviewed by: F. Kogan and two anonymous referees

\section{References}

Alley, W. M.: The Palmer Drought Severity Index: Limitations and assumptions, J. Clim. Appl. Meteorol. 23, 1100-1109, 1984.

Bonifacio, R., Dugdale, G., and Milford, J. R.: Sahelian rangeland production in relation to rainfall estimates from Meteosat, Int. J. Remote Sens., 14, 2695-2711, 1993.

Briffa, K. R., Jones, P. D., and Hulme, M.: Summer moisture variability across Europe, 1892-1991: an analysis based on the Palmer drought severity index, Int. J. Climatol., 14, 475-506, 1994.

Bussay, A., Szinell, C., and Szentimery, T.: Investigation and Measurements of Droughts in Hungary, Climatological and Agrometeorological Papers, 7. Hung. Meteor. Service, Budapest, 91 pp., 1999.

Diouf, A. and Lambin, E. F.: Monitoring land-cover changes in semi-arid regions: Remote sensing data and field observations in the Ferlo, Senegal, J. Arid Environ., 48, 129-148, 2001.

Eagleson, P.: Ecohydrology. Darwinian expression of vegetation form and function, Cambridge University Press, Cambridge, 488 pp., 2002.

EEA - European Environment Agency: Sustainable water use in Europe, Part 3: extreme hydrological events: floods and droughts, Env. Issue Report No. 21, 84 pp., 2001.

Estrela, M. J., Peñarrocha, D., and Millán, M.: Multi-annual drought episodes in the Mediterranean (Valencia region) from 1950-1996, A spatio-temporal analysis, Int. J. Climatol., 20, 1599-1618, 2000.

Feio, M. and Henriques, V.: As secas de $1980-81$ e de $1982-83$ e as principais secas anteriores - intensidade e distribuição regional,
Memórias do Centro de Estudos Geográficos, 10, 7-113, 1986 (in Portuguese).

Garcia-Herrera, R., Paredes, D., Trigo, R. M., Trigo, I. F., Hernández, H., Barriopedro, D., and Mendes, M. T.: The outstanding 2004-2005 drought in the Iberian Peninsula: the associated atmospheric circulation, J. Hydrometeorol., 8, 483-498, 2007.

Gibb, O., Penman, H. L., Pereier, H. C., and Ratcliffe, R. A. S.: Scientific Aspects of the 1975-76 Drought in England and Wales, The Royal Society, London, 133 pp., 1978.

Gouveia C. and Trigo R. M.: Infuence of Climate Variability on Wheat Production in Portugal, in: geoENV VI - Geostatistics for Environmental Applications, edited by: Soares, A., Pereira, M. J., and Dimitrakopoulos, R., Springer, 335-345, 2008.

Hagolle, O., Lobo, A., Maisongrande, P., Duchemin, B., and De Pereira, A.: Quality assessment and improvement of SPOT/VEGETATION level temporally composited products of remotely sensed imagery by combination of VEGETATION 1 and 2 images, Remote Sens. Environ., 94(2), 172-186, 2005.

Holben, B. N.: Characteristics of maximum-value composite images from temporal AVHRR data, Int. J. Remote Sens., 7, 14171434, 1986.

Iglesias, E., Garrido, A., and Gomez-Ramos, A.: Evaluation of drought management in irrigated areas, Agricultural Economics, 29, 211-229, 2003.

Karl, T.: The sensitivity of the Palmer drought severity index and Palmer's Z-index to their calibration coefficients including potencial evapotranspiration, J. Clim. Appl. Meteorol., 25, 77-86, 1986.

Kogan, F. N.: Application of vegetation index and brightness temperature for drought detection, Adv. Space Res., 11, 91-100, 1995.

Kogan, F. N.: Global drought watch from space, B. Am. Meteorol. Soc., 78, 621-636, 1997.

Kogan, F. N.: Contribution of remote sensing to drought early warning, in: Early warning systems for drought preparedness and drought management: Proceedings of an Expert Group Meeting, 5-7 September, Lisbon, Portugal, edited by: Wilhite, D. A., Sivakumar, M. V. K., and Wood, D. A., Geneva, Switzerland: WMO, 86-100, 2000.

Kogan, F. N., Usa, D. C., Stark, R., Gitelson, A., Jargalsaikhan, L., and Dugarjav, C.: Derivation of pasture biomass in Mongolia from AVHRR-based vegetation health indices, Int. J. Remote Sens., 25, 2889-2896, 2004.

Lana, X., Serra, C., and Burgueño, A.: Patterns of monthly rainfall shortage and excess in terms of the standardized precipitation index, Int. J. Climatol., 21, 1669-1691, 2001.

Lloyd-Hughes, B. and Saunders, M. A.: A drought climatology for Europe, Int. J. Climatol., 22(13), 1571-1592, 2002.

Los, S. O.: Linkages between global vegetation and climate: an analysis based on NOAA-Advanced Very High Resolution Radiometer Data, Ph.D. thesis, Vrije Universiteit, Amsterdam, 179 pp., 1998.

Lucht, W. I., Colin Prentice, W. I., Myneni, R. B., Sitch, S., Friedlingstein, P., Cramer, W., Bousquet, P., Buermann, W., and Smith, B.: Climatic Control of the High-Latitude Vegetation Greening Trend and Pinatubo Effect, Science, 296, 1687-1688, 2002.

MADRP: Relatório de balanço da seca, Ministério da Agricultura 
do Desenvolvimento Rural e Pescas, Lisboa, 106 pp., 2005 (in Portuguese).

Maisongrande, P., Duchemin, B., Dedieu, G.: VEGETATION/SPOT - An Operational Mission for the Earth Monitoring: Presentation of New Standard Products, Int. J. Remote Sens., 25, 9-14, 2004.

Marsh, T. J. and Lees, M. L.: The 1984 Drought, Institute of Hydrology, British Geological Survey, Wallingford, UK, 80 pp., 1985.

McCarthy, J. J., Canziani, O. F., Leary, N. A., Dokken, D. J., and White, K. S.: Climate Change 2001: Impacts, Adaptation and vulnerability, UK, Cambridge University Press, 1000 pp., 2001.

McVicar, T. R. and Jupp, D. L. B.: The current and potential operational uses of remote sensing to aid decisions on Drought Exceptional Circumstances in Australia: A Review, Agr. Sys., 57(3), 399-468, 1998.

McVicar, T. R. and Jupp, D. L. B.: Estimating one-time-of-day meteorological data from standard daily data as inputs to thermal remote sensing based energy balance models, Agr. Forest Meteor., 96, 219-238, 1999.

McVicar, T. R. and Jupp, D. L. B.: Using covariates to spatially interpolate moisture availability in the Murray-Darling Basin: A novel use of remotely sensed data, Remote Sens. Environ., 79, 199-212, 2002.

Miranda, P. M. A., Valente, M. A., Tomé, A. R., Trigo, R., Coelho, M. F., Aguiar, A., and Azevedo, E. B.: O Clima de Portugal nos séculos XX e XXI, in: Climate Change in Portugal: Scenarios, Impacts and Adaptation Measures - SIAM II Project, edited by: Santos, F. D., Forbes, K., and Moita, R., Gradiva, Lisbon, 47113, 2006 (in Portuguese).

Morales, A., Olcina, J., and Rico, A. M.: Diferentes percepciones de la sequía en España: adaptación, catastrofismo e intentos de corrección (The different perceptions about droughts in Spain: adaptations and correction systems, in Spanish), Investigaciones Geográficas, 23, 5-46, 2000 (in Spanish).

Nemani, R. R., Charles, D., Keeling, C. D., Hashimoto, H., Jolly, W. M., Piper, S. C., Tucker, C. J., Myneni, R. B., and Running, S. W.: Climate-Driven Increases in Global Terrestrial Net Primary Production from 1982 to 1999, Science, 300, 1560-1563, 2003.

Nicholson, S. E. and Farrar, T. J.: The influence of soil type on the relationships between NDVI, rainfall, and soil moisture in semiarid Botswana: I. NDVI response to rainfall, Remote Sens. Environ., 50, 107-120, 1994.

Nicholson, S. E., Davenport, M. L., and Malo, A. R.: A comparison of the vegetation response to rainfall in the Sahel and east Africa, using normalized difference vegetation index from NOAA-AVHRR, Climatic Change, 17, 209-241, 1990.

Nicholson, S. E., Tucker, C. J., and Ba, M. B.: Desertification, drought and surface vegetation: An example from the West African Sahel, B. Am. Meteorol. Soc., 79, 815-829, 1998.

Palmer, W. C.: Meteorological drought, US Department of Commerce Weather Bureau, Washington, DC, Research Paper No. 45, 65 pp., 1965.

Paredes D., Trigo, R. M., Garcia-Herrera, R., and Trigo, I. F.: Understanding precipitation changes in Iberia in early Spring: weather typing and storm-tracking approaches, J. Hydrometeor., 7, 101-113, 2006.

Phillips, I. D. , and McGregor, G. R.: The utility of a drought index for assessing the drought hazard in Devon and Cornwall, South
West England, Meteorol. Appl., 5, 359-372, 1998.

Rahman, H. and Dedieu, G.: SMAC: a simplified method for the atmospheric correction of satellite measurements in the solar spectrum, Int. J. Remote Sens., 15, 123-143, 1994.

Rodríguez-Iturbe, I. and Porporato, A.: Ecohydrology of watercontrolled ecosysytems, Cambridge, 460 pp., 2004.

Sannier, C. A. D. and Taylor, J. C.: Real-time vegetation monitoring with NOAAAVHRR in Southern Africa for wildlife management and food security assessment, Int. J. Remote Sens., 19, 621-639, 1998.

Scipal, K.: Global Soil Moisture Retrieval from ERS Scatterometer Data, Ph.D. thesis, Vienna University of Technology, Austria, 128 pp., 2002.

Sellers, P. J., Dickinson, R. E., Randall, D. A., Betts, A. K., Hall, F. G., Berry, J. A., Collatz, G. J., Denning, A. S., Mooney, H. A., Nobre, C. A., Sato, N., Field, C. B., and Henderson-Sellers, A.: Modeling the exchanges of energy, water, and carbon between continents and the atmosphere, Science, 275, 502-509, 1997.

Stöckli, R. and Vidale, P. L.: European plant phenology and climate as seen in a 20-year AVHRR land-surface parameter dataset, Int. J. Remote Sens., 25, 3303-3330, 2004.

Trigo, R. M. and DaCamara, C. C.: Circulation Weather Types and their impact on the precipitation regime in Portugal, Int. J. Climatol., 20, 1559-1581, 2000.

Trigo, R. M., Pereira, J. M. C., Pereira, M. G., Mota, B., Calado, M. T., DaCamara, C. C., and Santo, F. E.: Atmospheric conditions associated with the exceptional fire season of 2003 in Portugal, Int. J. Climatol., 26(13), 1741-1757, 2006.

Vermote, E. D., Tanré, J. L., Deuzé, M., Herman, M., and Morcrette, J. J.: Second simulation of the satellite signal in the solar spectrum, 6S: an overview, IEEE T. Geosci. Remote Sens., 35, 675-686, 1997.

Vicente-Serrano, S. M.: Spatial and temporal analysis of droughts in the Iberian Peninsula (1910-2000), Hydrol. Sci. J., 51, 83-97, 2006.

Vicente Serrano, S. M.: Evaluating the Impact of drought using Remote Sensing in a Mediterranean, semi-arid region, Nat. Hazards, 40, 173-208, 2007.

Vicente-Serrano, S. M. and Heredia-Laclaustra, A.: NAO influence on NDVI trends in the Iberian Peninsula (1982-2000), Int. J. Remote Sens., 25(14), 2871-2879, 2004.

Wagner, W., Lemoine, G., and Rott, H.: A Method for Estimating Soil Moisture from ERS Scatterometer and Soil Data, Remote Sens. Environ., 70(2), 191-207, 1999a.

Wagner, W., Lemoine, G., Borgeaud, M., and Rott, H.: A Study of Vegetation Cover Effects on ERS Scatterometer Data, IEEE T. Geosci. Remote Sens., 37(2), 938-948, 1999b.

Wilhite, D. A.: Understanding the Phenomenon of Drought, HydroReview, 12, 136-148, 1993

WMO - World Meteorological Organization: Drought monitoring and early warning: Concepts, progress and future challenges, 1006 pp., 2006.

Zhang, X., Wang, X. L., and Corte-Real, J.: On the relationships between daily circulation patterns and precipitation in Portugal, J. Geoph. Res, 102(D12), 13 495-13 507, 1997.

Zhou, L., Tucker, C. J., Kaufmann, R. K., Slayback, D., Shabanov, N., and Myneni, R. B.: Variations in northern vegetation activity inferred from satellite data of vegetation index during 1981 to 1999, J. Geophys. Res., 106(D17), 20 069-20 083, 2001. 